\title{
HPLC-UV METHOD FOR QUANTIFICATION OF SCHIZANDROL A IN RAT PLASMA: VALIDATION AND APPLICATION TO A PHARMACOKINETIC STUDY
}

\author{
(C) Karlina M. V., Pozharitskaya O. N., Kosman V. M.
}

Saint-Petersburg Institute of Pharmacy, Russia

Schisandrol A is the most abundant and active component (dibenzocyclooctadiene lignan) isolated from seeds of Schizandra shinensis. It possesses hepatoprotective, antiviral, antioxidant, cytotoxic, and cancer chemopreventive activities (1). The purpose of the present work was to develop and validate a simple and reliable method for the determination of schizandrol $A$ in rat plasma and to use it for the estimation of the pharmacokinetic parameters of schizandrol A. A simple, specific and sensitive RP-HPLC method with UV detection for the determination of schizandrol $A$ in plasma was developed and validated. From a variety of compounds and solvents tested, abietic acid was selected as the internal standard and acetonitril was found to be the best solvent for extracting schizandrol A from plasma. HPLC analysis of the extracts was performed on a $\mathrm{C}_{18}$ column $(4.6 \mathrm{~mm} \times 150 \mathrm{~mm}, 5 \mu \mathrm{m}$ particle size) equipped witch a guard pre-column (same sorbent $2.0 \mathrm{~mm}$ ). The mobile phase for gradient elution consisted of two solvent systems: solvent
A $0.03 \%(\mathrm{v} / \mathrm{v})$ water solution of trifluoroacetic acid; solvent B methanol. The UV detection was at $250 \mathrm{~nm}$. The elution time for schizandrol $A$ and abietic acid was approximately 7.3 and $25.9 \mathrm{~min}$, respectively. The calibration curve of schizandrol A was linear $(r>0.99)$ over the range $0.10-10 \mu \mathrm{g} / \mathrm{ml}$ in rat plasma. Recovery from plasma was $84-98 \%$. The limit of detection (LOD) and limit of quantification (LOQ) for schizandrol A were 0.03 and $0.10 \mu \mathrm{g} / \mathrm{m}$, respectively. The validated method was successfully applied to the pharmacokinetic study of schizandrol $A$ in rat plasma after single oral administration of Schizandra oil extract (dose of schizandrol A $5 \mathrm{mg} / \mathrm{kg}$ ). The basic pharmacokinetic parameters of schizandrol $A$ in rats were determined by noncompartmental analysis. The mean $\mathrm{AUC}_{0-\mathrm{t}}$ and $\mathrm{C}_{\max }$ were $3.26 \mathrm{~h} \cdot \mu \mathrm{g} / \mathrm{ml}$ and $0.56 \mu \mathrm{g} / \mathrm{ml}$ The peak plasma levels was achieved to 1.0 hour and the mean elimination half life was 3.06 hours.

Reference: 1. Min H. Y. et al. (2008) Bioorg. Med. Chem. Lett. 18: 523-526.

\section{DEVELOPMENT OF AN ANTIDIABETIC FUNCTIONAL DRINK ON THE BASIS OF BOTANICAL EXTRACT COMPLEX}

\author{
(C) Sorokin V. V., Kaukhova I.Ye., Medvedeva T. M., Samsonova Ye. A. \\ St. Petersburg State Chemical-Pharmaceutical Academy, Russia
}

Today diabetes mellitus (DM) is one of the three main causes of death after cardiovascular diseases and cancer. In Russia over the last 20 years DM morbidity is increasing. The purpose of this work was to develop a functional drink on the basis of extracts from medicinal plant, containing antihyperglycemic biologically active substances (BAS). The principal components of the functional drink were bean, blueberry shoots, rose hips and cranberry fruit. Analysis of the medicinal plant raw material was performed, main quality parameters were defined and the presence of main BAS groups was confirmed by qualitative reactions. To determine total carbohydrate in order to calculate the bread unit, the content of polysaccharides in the extracts was calculated. Optimum parameters of the extraction procedure for each plant raw material were determined. It was found that in order to maximize the yield of BAS it is reasonable to perform a simultaneous extraction of the raw complex material. We propose the following technology of the functional drink: obtaining an extract from a mixture of bean orals, blueberry, shoots and rose hips (extragent - water, method of extraction - maceration with mixing and heating to $60{ }^{\circ} \mathrm{C}$ ), obtaining an extract from cranberry fruit (extragent - ethanol $70 \%$, method of extraction - maceration with agitation and further solvent removal), pooling the extracts, sedimentation and filtration, addition of a preservative, correction of organoleptic properties, standardization, packaging and labeling. Standardization of the drink was made by the following characteristics: content of flavonoids, polysaccharides and glucose, alcohol by weight (ABW not more than $0.5 \%)$, dry solids weight ratio, microbial purity. 